Ankara Ecz. Fak. Der.

15. 58 (1985)
J, Fac. Pharm. Ankara

15. 58 (1985)

\title{
İç Anadolu Bölgesinde Böbrek Taşlarına Karşı Kullanilan Halk İlaçları
}

\author{
Folk Remedies for Renal Stones Used in \\ Central Anatolia Region
}

Sevgi ŞAR* Eriş ASİL*

\section{ÖZET}

Bu çalışmada İç Anadolu Bölgesi'nde böbrek taşlarına karşı kullanılan halk ilaçları incelenmiştir. Oral Tradisyon Tekniği kullanılarak toplanan materyal üzerinde Tip ve Eczacılık Tarihi ile Farmakognozi Bilimleri açısından değerlendirmeler yapılmış, istatistik sonuçlar elde edilerek konu tartışılmıştır.

Elde edilen sonuçlara göre İç Anadolu Bölgesi'nde 17 drogdan oluşan 16 ilaç böbrek taşlarına karşı kullanılmaktadır. Bu 17 droğun 15 tanesi bitkisel ve 2 tanesi hayvansal kaynaklıdır. 17 drogdan 2 tanesi günümüzde ilaç olarak modern tedavide kullanılmakta olup 15 tanesi tedaviden kaldırılmıştır.

\section{SUMMARY}

In this study, Folk Remedies for renal stones which are used in Central Anatolia Region have been investigated. The materials which are collected by using Oral Tradition Thecnic have been evaluated, some statistical results obtained and discussed from the point of view of History of Medicine and Pharmacy and Pharmacognosy.

According to the results: 16 folk remedies for renal stones which are formed 17 drugs have been being used in Central Anatolia Region. Of these, 15 drugs are obtained from plants and 2 drugs are animal

Reaksiyona verildiği tarih: 17.4.1985

*Eczacılık Tarihi ve İşletmeciliği Bilim Dalı, Eczacılık Fakültesi, Ankara Üniversitesi. 
İç Anadolu Bölgesi'nde Böbrek Taşlarına Karşı Kullanılan.

originated. Two of these 17 drugs are still used as remedy in our times and 15 of them are not used in modern therapy.

Anahtar Kelimeler: İç Anadolu Bölgesi, Böbrek Taşları, Halk İlac1.

Böbrek taşlarına bağlı kolikler çok sık rastlanan ve hastaya büyük izdiraplar veren rahatsızlıklardır. Kimyasal yapıları farklılıklar gösteren böbrek taşları bazen kendiliğinden düşmekte bazen de operasyonla alınmaları gerekmektedir. Böbrek koliklerinde hekim tavsiyesiyle kuvvetli ağrı kesici ve spazm çözücüler kullanıldı̆̆ı gibi bazı halk ilaçlarının da sıklıkla kullanıldığı bilinmektedir.

Bu çalışmada İç Anadolu Bölgesi'nde böbrek taşlarına karşı kullanılan halk ilaçları ele alınmış ve bunlar üzerinde Tıp ve Eczacılık Tarihi ile Farmakognozi açısından incelemeler yapılmıştır.

\section{A LAN ÇA L IŞ MALAR I}

\section{Materyal ve Metod}

Çalışmanın materyalini İç Anadolu Bölgesi'nde oturan halktan toplanan bilgiler oluşturmaktadır. Materyalin toplanması için uygulanan yöntem ise Sahada Folklor Derleme Yöntemlerinden en yaygını olarak bilinen Oral Tradisyon Tekniğidir (15). Tekniğin uygulanması için özel Kayıt Formları* geliştirilmiştir (28). Halk ilaçlarının yapısına giren ancak henüz drog olarak belirlenmemiş olan bitki ve bitki kısımlarının Lâtince isimleri verilmemiştir.

\section{İç Anadolu Bölgesi'nde Böbrek Taşlarına Karşı Kullanı- lan Halk Illaçları}

1. Bir avuç mısır püskülü suda kaynatılır, süzülür, süzüntüden günde üç çay bardağı içilir.

2. Bir avuç arpa bir miktar suda kaynatılıp süzülür, bir gece soğukta bekletilir. Bu süzüntüden sabah akşam birer çay bardağ 1 içilir.

*Araştırma ile ilgili formlar A.Ü. Eczacılık Fakültesi Eczacılık Tarihi ve İşletmeciliği Bilim Dalı Arşivi'ndedir. 
3. Bir tutam söğüt yaprağı bir bardak sıcak suda 15 dakika bekletilir süzülür ve içilir.

4. $1 \mathrm{~kg}$ kereviz $2 \mathrm{~kg}$ suyla kaynatılır, süzülür, süzüntüden günde bir çay bardă̆ı içilir.

5. Bir tutam kekik bir bardak sıcak suda 15 dakika bekletilir, süzülür, süzüntüden aç karına içilir.

6. Bir avuç ardıç tohumu dövülür, bir miktar bal ile karıştırılır, sabahları aç karına birkaç kaşık yenir.

7. Tavuk taşlığı zarı yıkanır, kurutulur, dövülür ve günde bir kahve kaşı̆̆ı içilir.

8. Bir tutam dövülmüş ısırgan otu tohumu bir bardak sıcak suda 10 dakika bekletilir, süzülür ve içilir.

9. Birer avuç mısır püskülü, arpa ve ayrıkotu kökü suda kaynatılır, süzülür, süzüntüden sabahları aç karına bir çay bardağı içilir.

10. Bir avuç iğde meyvası suda kaynatılır, süzülür, süzüntüden günde bir çay bardağı içilir.

11. Bir avuç kendir tohumu $1 \mathrm{~kg}$ sütte kaynatılır, süzülür, süzüntüden günde 3 defa birer fincan içilir.

12. Bir miktar bögürtlen kökü suda kaynatılır, süzülür, süzünden sabahları aç karına birer fincan içilir.

13. Bir tutam pelinotu bir bardak sicak suda 10 dakika bekletilir, süzülür, süzüntü aç karına içilir.

14. Bir avuç kiraz sapı bir litre suda kaynatılır, süzülür, süzüntü bir gece soğukta bekletildikten sonra sabah akşam birer fincan içilir.

15. Aç karına bir çay kaşı̆̆ı tere tohumu yenir.

16. Bir tutam papatya çiçeği bir çay bardağı sıcak suda 10 dakika bekletilir, süzülür, süzüntü sabahları içilir. 


\section{İç Anadolu Bölgesi'nde Böbrek Taşlarına Karşı Kullanilan Halk İlaçlarının İçerdiği Drogların İncelenmesi}

\section{Ardiç Meyvasi, Fructus Juniperi}

Bölgede doğal olarak yetişen Juniperus foetidissima, juniperus sabina ve juniperus oxycedrus (Cupressaceae) bitkilerinin kurutulmuş meyvalarıdır. Foetidissima meyvalarının halkın kullandı̆̆ı tarzda kullanıldı̆̆ına dair literatürde herhangi bir kayda rastlanmamıştır. Juniperus sabina bitkisinin dal uçları kullanılır ve emenagog etkilidir. Düşük dozlarda uterus kanamalarına karşı kullanılır. Meyvaların kullanıldı ̆̆ına dair bir kayıt bulunmamaktadır. Juniperus oxycedrus' un kullanılan kısmı ise odunundan elde edilen katrandır (19).

Eski Mezopotamya'da drog olarak kullanılan ardıç tohumu (23), Dİ O S C O Rİ DES'in (16) eserinde de kayıtlıdır.

Ardıç meyvasının Ege Bölgesi'nde halk arasında böbrek kum ve taşlarını düşürücü olarak kullanıldı̆̆ı kaydedilmekte ise de (24) bu etkiyi sağlayacă̆ı tarafımızca şüphe ile karşılanmaktadır.

\section{Arpa, Fructus Hordei (28)}

Droğun halkın kullandığı amaçla kullanılışına literatürde rastlanmamıştır.

\section{Ayrikotu Kökü, Rhizoma Graminis}

İç Anadolu Bölgesi'nde doğal olarak yetişen Agropyrum repens (Gramineae) bitkisinin kurutulmuş rizomlarıdır. Droğun bileşiminde uçucu yağ, agropiren, müsilaj, Ca ve $\mathrm{K}$ tuzları, tritisin isimli özel bir karbonhidrat vardır (8, 19). 1930, 1940 ve 1948 Türk Kodekslerine kayıtlı olan Rhizoma Graminis'in diüretik etkisi bilinmektedir $(6,8$, 19, 20). B A Y T O P (8), bu etkinin taşıdı̆̆ K tuzlarından ileri geldiğini bildirmektedir. ÇELEB İ OĞLU (11), ayrıkotunun depüratif, tonik ve diüretik olarak kullanıldı̆̆ından bahsetmektedir.

Çok eski devirlerden beri tanınan ayrıkotu kökü, eski Mısır ÇarŞısında kum ve taş düşürücü olarak satılırdı (25). Osmanlılar ve Anadolu Selçukluları devrinde kum düşürücü ve idrar artırıcı olarak kullanıldığ 1 bilinmektedir $(2,3)$. Ege Bölgesi'nde halk arasında da kum düşürücü ve idrar artırıcı olarak kullanılmaktadır (24). 
Droğun idrar söktürücü etkisiyle mekanik olarak böbrek kum ve taşlarının düşmesine yardımcı olabileceği düşüncesindeyiz. Bu nedenle halkın droğu bu amaçla uygun olarak kullandığı söylenebilir.

\section{Bal, Mel (4)}

Droğun halkın kullandığı amaçla kullanılışına literatürde rastlanmamıştır.

\section{Böğ̈̈rtlen Kökü, Radix Rubi}

İç Anadolu Bölgesi'nde doğal olarak yetişen Rubus (Rosaceae) türlerinin gölgede kurutulmuş kökleridir. Bögürtlen köklerinde tanen bulunmaktadır (11). Bögürtlenin kökleri ve meyvaları astrenjan ve tonik olarak kullanılmıştır $(10,11,21)$.

Anadolu Selçukluları ve Osmanlılar devrinde $(2,3)$ idrar artırıcı olarak kullanılan böğürtlen kökü, eski Mısır Çarşısında aynı amaç için aranırdı (12).

Droğun halk arasında böbrek kum ve taşlarını düşürmede yarar sağlayacağı şüpheli görülmektedir.

\section{Isirgan otu, Herba Urticae}

İç Anadolu Bölgesi'nde doğal olarak yetişen Urtica dioica ve Urtica urens (Urticaceae) bitkilerinin toprak üstü kısımlarıdır. Droğun bileşiminde histamin, formik asit, klorofil, urticosit, nitratlar (kalsiyum, potasyum) bulunmaktadır (10, 11, 19). Eskiden bitkinin tüyleri içindeki özel yakıcı bir madde olan formik asit nedeniyle kronik rahatsızlıklarda, dahilen iç organ kanamalarında kan kesici olarak, haricen egzema ve yaralarda kullanılmıştır (17). Eskiden kanı iç organlardan çevreye çekmekte, romatizmada, siyatikte, saç dökülmelerinde ve burun kanamalarında isırgan otu yapraklarından hazırlanan infüzyonu kullanılmaktaydı (7). Droğun, diüretik, dépuratif, antidiabetik, antiromatizmal, astringen, hemostatik, antianemik, kolagog, stimülan, vazokonstriktör etkileri bilinmektedir $(10,11,19,21)$.

Isırgan otu çok eski devirlerden beri tanınan bir drogdur. Dİ OS C O RİDES (16), droğun antiromatizmal, diüretik, emenagog ve hemostatik olarak kullanıldığından bahsetmektedir. Osmanlılar devrinde (2) mayasılda, Anadolu Selçukluları devrinde (3) cilt hastalıkların- 
da kullanılmıştır. Eski Mısır Çarşısında hemoroid tedavisi için çok satılan drog (12), Ege Bölgesi halk hekimliğinde sivilce, yara, kanser ve diğer bazı cilt hastalıklarında kullanılmaktadır (24).

Droğun idrar söktürücü etkisiyle mekanik olarak böbrek kum ve taşlarının düşmesine yardımcı olabileceği düşüncesindeyiz. Bu nedenle halkın droğu bu amaçla uygun olarak kullandı̆̆ 1 söylenebilir.

\section{İğde Meyvası, Frustus Eleagni}

İç Anadolu Bölgesi'nde kültürü yapılan Eleagnus angustifolia (Eleagnaceae) bitkisinin meyvalarıdır.

Drog, Osmanlılar devrinde öksürük kesici olarak kullanılmıştır (2). S UCU (24), iğde yapraklarının Ege Bölgesi'nde halk arasında böbrek kum ve taşlarını düşürücü olarak kullanıldı̆̆ını yazmaktadır.

Droğun, halkın kullandı̆̆ 1 alanda yarar sağlayacağı şüpheli görülmektedir.

\section{Kekik Otu (4)}

Halkın "Kekik Otu" adı verdiği ve böbrek taşlarına karşı kullandığ 1 bitkinin cins ve türü hakkında kesin bir bilgi sağlanmamıştır. Halk, timol ve karvakrol'ün karakteristik kokusunun duyulduğu her bitkiye "kekik" demektedir. Ancak timol ve karvakrolün halkın kullandığ 1 tarzda bir etkisi bilinmemektedir. Bu nedenle halkın "kekik otu" olarak adlandırdığı bitkinin etkisi hakkında kesin bir görüş bildirmek mümkün değildir.

\section{Kendir Tohumu, Fructus Cannabis}

Kayseri, Sivas, Konya, Kütahya, Antalya yörelerinde kültürü yapılan Cannabis sativa (Cannabinaceae) bitkisinin meyvalarıdır. Bileşiminde protein, vitamin $\mathrm{K}$ ve sabit yă bulunmaktadır. Bitkinin dişi çiçekli dal uçlarında (Herba Cannabis) uçucu yă ve tetrahydrocannabinol ihtiva eden reçine bulunmaktadır $(7,8,19,27)$. Dişi çiçekli dal uçlarının salgıladı̆̆ı reçineli madde kurutularak uyuşturucu ve zehirli bir madde olan esrar elde edilmektedir $(7,18,19)$.

Herba Cannabis merkezi sinir sistemine tesir eden bir yatıştırıcı ve uyuşturucudur (7). 
Eski çağlardan beri tanınan drog, Sümerler zamanında kullanılmış olup, Mezopotamya Kodeksinde kayıtlıdır (25). Esrar otunu ilk defa narkotik olarak Çinli bir cerrah olan Hua-Tu kullanmıştır (13). Drog, Osmanlılar devrinde (2) idrar artırıcı olarak kullanılmıştır.

Droğun bilinen yapı ve etkileri gözönüne alındığında halkın kullandığı alanda yarar sağlayacağı şüpheli görülmektedir.

\section{Kereviz Yapră̆ı, Folia Apii}

Apium graveolens (Umbelliferae) bitkisinin yapraklarıdır. Bitkinin bileşiminde flavonoit, apiosid, apigenol heteroziti bulunmaktadır (10). Droğun, eupeptik ve taşıdı̆̆ Apiosid'den dolayı diüretik etkileri bilinmektedir $(10,21)$.

D İ O S C O R İ D E S (16), droğun göz iltihaplarında ve mide yanmalarında kullanıldı̆̆ından bahsetmektedir. İBNİ SİNA'nın (22) da kaydettiği droğu Hİ P POCRATES idrar söktürücü olarak tavsiye eder (5).

Droğun idrar söktürücü etkisiyle mekanik olarak böbrek taş ve kumlarının düşmesine yardımcı olabileceği düşüncesindeyiz. Bu nedenle halkın droğu bu amaçla uygun olarak kullandı̆̆ 1 söylenebilir.

\section{Kiraz Sapı}

İç Anadolu Bölgesi'nde kültürü yapılan Prunus avlum (Rosaceae) bitkisinin meyva saplarıdır. Kiraz sapının diüretik etkisi bilinmektedir $(1,10,21)$.

Droğun idrar söktürücü etkisiyle mekanik olarak böbrek taş ve kumlarının düşmesine yardımcı olabileceği düşüncesindeyiz. Bu nedenle halkın droğu bu amaçla uygun olarak kullandığı söylenebilir.

\section{Misir Püskülü, Stylus Maydis}

İç Anadolu Bölgesi'nde kültürü yapılan Zea mays (Gramineae) bitkisinin dişi çiçeklerinin kurutulmuş uzun styluslarıdır. Mısır Püskülü şekerler (glikoz, maltoz), sabit yağ, steroller, reçine, tanen, uçucu yağ, saponin, flavon, karbon hidratlar, tuzlar ve mum ihtiva etmektedir $(7,8,19)$. 1930, 1940 ve 1948 Türk Kodekslerine kayıtlı olan drog, eskiden idrar söktürücü, idrar yolları temizleyici ve taş düşürücü 
olarak infüzyon ve dekoksiyon halinde kullanılmıştır (7, 8, 19, 21). A L T I N K U R T (1), mısır püskülünün doğal diüretik olarak kullanıldiğım kaydetmektedir.

İ B İ S İNA'nın (22) eserinde ilaç olarak kayıtlı olan drog, Osmanlılar devrinde (2) idrar söktürücü olarak kullanılmaktaydı. X IX yüzyılda Mısır Çarşısında çok satılan drog (12), Ege Bölgesi'nde halk arasında idrar artırıcı, böbrek kum ve taşlarını düşürücü olarak kullanılmaktadir (24).

Droğun idrar söktürücü etkisiyle mekanik olarak böbrek taş ve kumlarının düşmesine yardımcı olabileceği düşüncesindeyiz. Bu nedenle halkın droğu bu amaçla uygun olarak kullandığı söylenebilir.

\section{Papatya, Flores Chamomillae (28)}

Droğun bilinen yapısı ve etkileri gözönüne alındığında, halkın kullandığı alanda yarar sağlayacağı şüpheli görülmektedir.

\section{Pelinotu, Herba Absinthii (28)}

Droğun bilinen yapısı ve etkileri gözönüne alındığında halkın kullandı̆̆ 1 alanda yarar sağlayacağı şüpheli görülmektedir.

\section{Söğüt Yapră̆ı, Folia Salicis}

İç Anadolu Bölgesi'nde doğal olarak yetişen Salix alba (Salicaceae) bitkisinin yapraklarıdır. Bitkinin kabuklarında tanen, reçine ve glikozit taşımaktadır $(6,7,8)$. Kabukların iştah açıcı, kabız, ateş düşürücü, kuvvetlendirici, antiromatizmal, antispazmodik, astringen etkileri bilinmektedir $(6,7,8,9,21,26)$.

Eski devirlerden beri kullanılmakta olan droğa, M. Ö. 7-8. yüzyıla ait tıbbî tabletlerde ve antik Mısır'da rastlanmıştır (5). DİOSCORİDES (16), tedavide sögüt yaprağını kullandığını bildirmektedir. Osmanlılar devrinde (2) egzemada kullanılmıştır.

Droğun halk arasında kullanıldığı alanda yarar sağlayacağı şüpheli görülmektedir.

\section{Tavuk Taşlığı Zarı}

Tavukta, halk dilinde "taşlıca" adıyla anılan adali midenin mukozası, boynuz gibi sert, koyu renkli ve uzunlamasına dürümlüdür. 
Bu mukozanın dış yüzü boynuzlaşmış, homojen ve sert bir tabaka ile örtülüdür. Bu sert tabaka, mukoza içerisindeki bezler tarafından yapılan salgının, modifiye olarak sertleşmesi neticesinde meydana gelmiştir (14).

Tavuk taşlı̆̆ı zarı üzerinde çalışmalar devam etmektedir. Bu nedenle halkın kullandığı alanda yarar sağlayıp sağlamayacağı konusunda karar verilememiştir.

\section{Tere Tohumu (4)}

Droğun halkın kullandığı alanda yarar sağlayacağı şüpheli görülmektedir.

\section{SONUÇ ve TARTIŞMA}

Bu araştırmada İç Anadolu Bölgesi'nde halk arasında böbrek taşlarına karşı 16 ilaç terkibinin kullanıldığı saptanmıştır. Bu ilaçlar 17 drogdan yapılmaktadır. Böbrek taşlarına karşı kullanılan halk ilaçları bölgede kullanıldığı saptanan tüm halk ilaçlarının (926 adet) \% 1.73 ünü oluşturmaktadır*.

\section{Bu 17 drogdan}

15 tanesi bitkisel

2 tanesi hayvansal kaynaklıdır.

* Bu bitkilerden:

8 tanesi bölgede doğal olarak yetişmekte,

6 tanesinin bölgede kültürü yapılmakta,

1 tanesinin yöre dişında hem kültürü yapılmakta hem de doğal olarak yetişmektedir.

17 drogdan, 2 tanesi günümüzde ilaç olarak kullanılmakta, 15 tanesi ise ilaç olarak kullanılmamaktadır.

$\mathrm{Bu}$ araştırmada halk arasında böbrek taşlarına karşı kullanıldığı saptanan drogların pekçoğu eski devirlerden beri bilinmekte ve klasik yazarlarca ilaç olarak kaydedilmektedir.

Halkın ilaç olarak kullandığ 17 drogdan 6 tanesi bilinen etkilerine uygun olarak kullanılmaktadır. 11 tanesinin ise kimyasal yapıları

*Ankara Üniversitesi Eczacılık Fakültesi Eczacılık İşletmeciliği ve Tarihi Bilim Dalı Arşivi. 
ve bilinen etkileri dikkate alındığında böbrek kum ve taşlarını düşürücü etki sağlamalarını şüpheyle karşılamaktayız.

Halk arasında kullanılışlarını uygun olarak nitelediğimiz drogların hepsi diüretik etkili droglardır. Bu droglar diüretik etkileri ile mekanik olarak böbrek taş ve kumlarının sürüklenmelerine ve düşmelerine yardimci olabilmektedir. Drogların etkilerini sistemik bir etki olarak nitelemek mümkün değildir. Eğer bu drogların gerçekten böbrek taşlarını düşürücü etkileri olsaydı günümüzde böbrek sancısı çeken hasta kalmazdı.

\section{LITERATÜR}

1- Altınkurt, O., Farmakoloji (I), Ankara Üniversitesi Basımevi, Ankara (1981).

2- Asil, E., Osmanlı Saray Eczacılığı ve Osmanlılar Devrinde Kullanılan Drogların Farmakoloji ve Farmakognozi Yönünden İfade Ettiği Değerler (Doktora Tezi), A.Ü. Eczacılık Fakültesi, Ankara (1974).

3- Asil, E., Anadolu Selçukluları Devri Tıp ve Eczacılık Kurumu (Doçentlik Tezi), Ankara (1979).

4- Asil, E., Tanker, M., Şar, S., İç Anadolu Bölgesi'nde Baş Ağrılarına Karşı Kullanılan Halk İlaçları, Ankara Üniversitesi Eczacılık Fakültesi Mecmuası, 14 (1), 67-80 (1984).

5- Baylav, N., Eczacılık Tarihi, Yörük Matbaası, İstanbul (1968).

6- Baytop, A., Farmasötik Botanik, Baha Matbaası, İstanbul (1977).

7- Baytop, T., Türkiye'nin Tıbbi ve Zehirli Bitkileri, İsmail Akgün Matbaası, İstabul (1963).

8- Baytop, T., Farmakognoziye Giriş, İsmail Akgün Matbaası, İstanbul (1966).

9- Baytop, T., Farmakognozi Ders Kitabı (2), Baha Matbaası, İstanbul (1971).

10- Bezanger Beauquesne, L., Pınkas, M., Torck, M., Les Plantes Dans la Therapeutique Moderne, Editör: Maloine S.A. 27, ruede l'Ecole de Medicine, 75006 Paris (1975).

11 - Çelebioglu, S., Farmakognozi Repetitorium, Çelik Cilt Matbaası, İstanbul (1963).

12- Demirhan, A., Mısır Çarşısı Drogları (Doktora Tezi), Sermet Matbaası, İstanbul (1975).

13- Demirhan, A., Geçmişte ve Günümüzde Esrar, İ. Ü. Ístanbul Tip Fakültesi Mecmuasl, 42 (79), İstanbul (1979).

14- Erençin, Z., Özel Histoloji (Mikroskopik Anatomi), Ankara Üniversitesi Basımevi, Ankara (1971). 
15- Goldstein, K.S., Sahada Folklor Derleme Metodları (Çev. Ahmet E. Uysal), Başbakanlık Basımevi, Ankara (1977).

16- Gunther, R.T., The Greek Herbal of Dioscorides, Hafner Publishing Co, New York (1959).

17- Güley, M., Samsun ve Trabzon Bölgesi Tıbbi ve Zehirli Bitkilerden Başlıcalarının Farmakodinamik Etkileri ve Tedavideki Önemleri (Doktora Tezi), A.Ü. Basımevi, Ankara (1953).

18-Güven, K.C., Tıbbi Formüler, İstanbul (1979).

19- Karamanoğlu, K., Farmasötik Botanik Ders Kitabı, A.Ü. Ecz. Fak. Yayınları, Sayı: 24, Ankara (1973).

20- Perrot, E., Paris, R., Les plantes Medicinales (I) Presses Unıversitaires de France (1971).

21-Perrot, E., Paris, R., Les plantes Medicinales (2), Presses Unıvesitaires de France (1971).

22- Said, H.M., Al- Birunî's Book on Pharmacy and Materia Medica, Hamdard National Foundation, Pakistan, Karachi (1973).

23- Sigerıst, H.E., A History of Medicine, Oxford University Press, New York (1951).

24- Sucu, İ., Ege Bölgesi Halk İlaçları ve Bu İlaçlardaki Drogların Farmakognozik İncelenmesi (Doktora Tezi), Ankara (1978).

25- Şehsuvaroğlu, B.N., Eczacılık Tarihi Dersleri, Hüsnütabiat Matbaası, İstanbul (1970).

26- Tanker, M., Tanker, N., Farmakognozi (I), Özışık Matbaası, İstanbul (1973).

27- Tanker, M., Tanker. N., Farmakognozi Cilt 2, Reman Matbaası, İstanbul (1976).

28- Tanker, M., Asil, E., Şar, S., İç Anadolu Bölgesi'nde Ateş Düşürücü Olarak Kullanılan Halk İlaçlan, Ankara Üniversitesi Eczacıllk Fakültesi Mecmuası, 13 (1,2), 193-205 (1983). 